\title{
A Macroeconomic Model on the Quality of Government and Economic Performance
}

\author{
Te-Tsun Chang \\ National Chi Nan University
}

\author{
Yiting $\mathrm{Li}^{*}$
}

National Taiwan University

September 2009

\begin{abstract}
We determine the relative rewards to and allocation of talent between producers, private rent-seekers and bureaucrats in a general equilibrium model. Unproductive activity creates a negative externality on the relative rewards to producers. If the size of bureaucracy is exogenously given, among the multiple equilibria, the one with fewer private rent-seekers yields higher welfare. By choosing a small size of bureaucracy, the government can establish the superior equilibrium as the unique outcome, which also achieves the constrained optimum. If the population of bureaucrats is endogenously determined, however, a larger bureaucracy enhances production and welfare. The size of government and economic performance are jointly determined, and their relationship depends on the quality of government. Our result supports the view that the size of government may not matter much; what is important is the quality of government.
\end{abstract}

Keywords: Rent-seeking; Quality of Government; Size of Government JEL Classification: E60; E61; H00

${ }^{*}$ Chang: Department of Economics, National Chi Nan University, No.1 University Rd, Puli, Nantou County 54561, Taiwan. e-mail: ttchang@ncnu.edu.tw. Li: Department of Economics, National Taiwan University, 21 Hsu-Chow Road, Taipei 10020, Taiwan. e-mail: yitingli@ntu.edu.tw. We thank an anonymous referee and associate editor for valuable comments and suggestions. We also thank Jang-Ting Guo, Nobu Kiyotaki, Ping Wang and participants in the 2007 Econometric Society Far Eastern Meetings at Taipei for helpful comments and conversations. 


\section{Introduction}

The empirical analysis of Hall and Jones (1999) suggests that the fundamental determinant of a country's economic performance is its social infrastructure - the institutions and government policies that provide incentives for individuals. Those incentives can encourage productive activity or predatory behavior like rent-seeking and corruption. Although suppression of rent-seeking appears to be most efficient if it is carried out by the government, the power to make and enforce rules makes the government itself particularly prone to expropriation. For instance, while bureaucrats protect property by suppressing private rent-seeking that interferes with productive activity, they may also seek rents themselves by soliciting bribes from citizens. ${ }^{1}$ How do the efficiency of bureaucrats in protecting property rights and the degree of their corruption affect the relative rewards received by producers, private rent-seekers and bureaucrats? And, how does the reward structure interact with the allocation of talent between productive and unproductive activity and, hence, influence a country's economic performance? ${ }^{2}$

To address the above issues, we work with an essentially standard macroeconomic model of production and trade externality based on Diamond (1982), in which productive activity is subject to private and public expropriation. Private rent-seekers and bureaucrats do not produce; they are completely dependent on producers' efforts. One important feature is the presence of a negative externality the unproductive activity exerts on the relative rewards that determine the allocation of agent across activity (see Murphy et al., 1993). We first consider, as a benchmark, a model where the size of bureaucracy is exogenously given, and then endogenize it as an individual's choice.

Under an exogenous bureaucracy, an agent chooses to be a producer or a private rentseekers. Producers conduct transactions in the decentralized markets. More productive activity yields higher returns to both producers and private rent-seeker, and this strategic complementarity results in Pareto rankable multiple equilibria. The equilibrium with a larger population of producers and less rent-seeking features higher welfare. By choosing

\footnotetext{
${ }^{1}$ We define rent-seeking as activity that relocate output, such as crime, violence, theft and robbery.

${ }^{2}$ For historical examples and empirical studies on the relation between the allocation of talent and rent-seeking, see Baumol (1990) and Murphy et al. (1991), respectively.
} 
a small size of bureaucracy, the government can establish the superior equilibrium as the unique outcome, that also achieves the constrained optimum. Social welfare, however, is decreasing in the size of bureaucracy in this equilibrium. The implication is that, the smaller the size of bureaucracy, the higher the welfare.

The optimal size of bureaucracy depends on two opposite influences on producers' incentives. One is the positive effect through better property rights protection. The other includes the various negative effects due to corruption, tax burdens and the fact that resources taken up in the public sector could otherwise be devoted to production. If the population of bureaucrats is endogenously determined, equilibria exist as long as bureaucrats' efficiency is high and corruption is low. The equilibrium with a larger bureaucracy is associated with higher production and welfare. The reason is that, with sufficient efficiency in deterring private rent-seeking and low corruption, a larger bureaucracy makes private production more profitable by reducing resources allocated to private rent-seeking, and the resulting externality further improves the relative rewards to productive activity. In general, the equilibrium size of the bureaucracy is not optimal. One resulting implication is that, for the equilibrium with a smaller bureaucracy, society would benefit by increasing the size of bureaucracy despite the fact that bureaucrats are corrupt.

Many believe that the size of government is an important factor for determining economic performance; however, Hall and Jones (1999, p. 111), argue that the characteristics of an economy such as the size of government should better be thought as outcomes rather than determinants. The current paper provides a natural framework to examine this issue. The size of government, defined as government spending relative to output per capita, and economic performance, measured as output per capita, are jointly determined in the model. If the size of bureaucracy is exogenously given, the relationship between the size of government and output per capita is always negative. If it is endogenously determined, this relationship depends on the efficiency of property rights protection and the degree of corruption. Hence, the size of government may not be as influential as once thought; what is important is the quality of government.

Our paper is related to studies on crime and economic activity; e.g., Burdett et al. 
(2003) discuss a similar mechanism for the presence of multiple equilibria: If workers are less inclined to criminal activity, firms are more willing to pay higher wages, which reduce workers' incentive to commit crimes. ${ }^{3}$ Among the related literature on bureaucracy and economic activity, Acemoglu (1995) studies the determination of reward structure and allocation of talent between producers and bureaucrats who do nothing but solicit bribes, and Acemoglu and Verdier (1998) consider bureaucrats help resolve the contractual issues between entrepreneurs. Using a model similar to Diamond (1982) as the basic framework, $\mathrm{Li}$ and Wright (1998) consider government agents that adopt some transaction rules to establish a certain object as the medium of exchange, and Shi and Temzelides (2004) consider the role of bureaucrats as inspecting the quality of private agents' products; however, both papers assume exogenous size of bureaucracy. A distinctive feature of the current paper is that we consider the role of bureaucracy in protecting property rights and soliciting bribes in a general equilibrium model, determine jointly the reward structure and allocation of talent, and discuss the welfare implications of the endogenous size of bureaucracy.

The rest of the paper is organized as follows. Section 2 presents the environment. In section 3 we study a model with an exogenous bureaucracy, and in Section 4 we endogenize it as an agent's choice and study welfare and policy implications. Section 5 concludes.

\section{Environment}

We work with a macroeconomic model of production and trade based on Diamond (1982). This model is a natural framework to study the negative externality on the incentive to

\footnotetext{
${ }^{3}$ There are some empirical studies in police and crime. For example, Cameron (1998) surveys a majority of papers and finds that there may be a positive relationship between police and crime, but an endogeneity problem makes it hard to isolate the causal relationship. Recent studies, such as Levitt (1997), Di Tella and Schargrodsky (2004) and Klick and Tabarrok (2005), use different approaches to resolve the endogeneity problem and find that police does deter crime. A theoretical paper by Kugler et al. (2005) finds that with endogenous corruption, increasing policing and sanctions can generate higher crime rates.
} 
produce caused by private rent-seekers' interference with the market activity.

Time is discrete. There is a $[0,1]$ continuum of infinitely lived agents with a common discount rate $r$. There is a special good for consumption that agents produce and trade in the market. An agent can produce at most one unit of special good at a time with a $\operatorname{cost} c_{p}$ in terms of disutility. Consuming one unit of special good yields utility $U>c_{p}$, if it is produced by someone else. An agent derives no utility from consuming his own production. This is a simple setup to generate the motive for trade. The special good is freely disposable, indivisible and storable at zero cost, but only one unit at a time. As a result, trade involves one-for-one swap of goods in the market.

In order to model the tax payment for bureaucrats' wages while preserving the simple structure of one-for-one swap of goods, we assume that agents can produce a general good (called 'tax good') with the following linear technology: producing $q$ units of the tax good generates disutility $q$. Consuming $q$ units of tax good yields utility $q$. Therefore, people have no incentives to produce tax good to trade in the market. The tax good is freely disposable, divisible and non-storable across periods.

An agent has three choices for his occupation: a producer-trader (hereafter denoted 'producer'), a private rent-seeker, or a bureaucrat (though this choice is restricted in the benchmark model of Section 3). To become a private rent-seeker or a bureaucrat, an agent must give up his technology of producing consumption goods. Therefore, private rent-seekers and bureaucrats do not produce; they depend completely on producers' efforts. Let the measure of bureaucrats, producers and private rent-seekers be $P_{b}, P_{p}, P_{\gamma}$, respectively, and $P_{b}+P_{p}+P_{\gamma}=1$.

Producers trade special goods in the decentralized markets where trading history is private information and there is no technology to enforce contracts. Thus, credit is infeasible and all trades must be quid pro quo. We assume the probability that an agent meets a bureaucrat, a private rent-seeker or a producer is the respective population proportion. This creates natural externality from individuals' choices of occupation on the return to production - trade is easier if more agents choose production and less resources are allocated to unproductive activity. An additional difficulty to trade comes from the presence of private rent-seekers' interference with the market activity: a producer's good 
will be exploited by private rent-seekers with some probability, which depends on the efficiency of bureaucrats in suppressing private rent-seeking.

The role of government is to collect taxes from producers as wages to bureaucrats. The government collects $\tau$ units of the tax good from each producer, and use the tax payments to offer a given wage rate $w$ to bureaucrats. The government budget constraint is

$$
P_{b} w=P_{p} \tau
$$

The bureaucrats' suppression of private diversion is modeled as an intimidation function, frightening the private rent-seekers not to commit a crime. We assume that the intimidation function is a function of the population of bureaucrats, denoted as $e\left(P_{b}\right)$, where $e^{\prime}>0, e^{\prime \prime} \leq 0$ and $e(0) \geq 0 .{ }^{4}$ One can interpret $e\left(P_{b}\right)$ as a government production function, which produces safety, and works better if there are more (labor hours of) bureaucrats (see Barreto, 2000 for a similar setup). That is, the government uses real resources, here bureaucrats, to provide public goods. With this setup, it follows that private rent-seekers successfully exploit producers' goods with probability $1-e\left(P_{b}\right)$. Notice that, unlike the totally unproductive private rent-seekers, bureaucrats are 'productive' in the sense that they protect producers from private rent-seeking.

While bureaucrats protect property by suppressing private rent-seeking that interferes with productive activity, they may also seek rents themselves by soliciting bribes from citizens. To capture the effect of bureaucrats' expropriation on private production, Acemoglu (1995) assumes that a bureaucrat solicits bribes by taking away a portion of producer's good when they meet. Following Acemoglu's setup, we assume that a bureaucrat solicits bribes from a producer by expropriating his output with probability $\phi .{ }^{5}$ That is, the expected loss to a producer when meeting a bureaucrat is $\phi$ multiplied by the production cost that have been devoted to produce the goods. We interpret $\phi$ as the degree of corruption. In general, one can endogenize the corruption of bureaucrats,

\footnotetext{
${ }^{4}$ One explicit form of $e\left(P_{b}\right)$ we consider in the paper is $\alpha P_{b}^{\beta}$, where $0<\alpha<\infty$ and $0<\beta \leq 1$.

${ }^{5}$ In our model goods cannot be stored if divided, so we modify Acemoglu's setup to a probability with which a bureaucrat takes away the whole unit of good. Notice that both setups are the same in the ex ante sense.
} 
but for simplicity, we treat $\phi$ as a factor determined by the social infrastructure. Our focus is on how institutional factors such as the degree of corruption and the efficiency of bureaucrats in suppressing private diversion affect the reward structure, allocation of talent and economic performance.

\section{An exogenous bureaucracy}

We first study the model with the population of bureaucrats exogenously given. As a benchmark, this serves as a starting point to understand the mechanisms underlying the determination of the reward structure and allocation of talent.

Let $V_{p}$ and $V_{\gamma}$ denote the expected lifetime utility to a producer and a private rentseeker, respectively. Let $\Pi=\max \left(V_{p}-c_{p}, V_{\gamma}\right)$ represent the expected value to a private agent who holds no inventory and chooses his occupation. The expected lifetime utility satisfies the following Bellman equations:

$$
\begin{aligned}
& r V_{p}=-\tau+P_{p}\left(U+\Pi-V_{p}\right)+P_{b} \phi\left(\Pi-V_{p}\right)+P_{\gamma}\left[1-e\left(P_{b}\right)\right]\left(\Pi-V_{p}\right), \\
& r V_{\gamma}=P_{p}\left[1-e\left(P_{b}\right)\right] U+\Pi-V_{\gamma} .
\end{aligned}
$$

Equation (2) says that the flow value to a producer is the gain from trading with other producers minus the losses due to paying taxes, being solicited bribe by bureaucrats, and being robbed by private rent-seekers. Notice that a producer has the probabilities $\phi$ and $1-e\left(P_{b}\right)$ of losing his output when meeting a bureaucrat and private rent-seeker, respectively, and if the events occur, he acquires the expected payoff $\Pi-V_{p}$. Equation (3) states that the flow payoff to a private rent-seeker is the probability of meeting a producer and successfully robbing his output, $P_{p}\left[1-e\left(P_{b}\right)\right]$, multiplied by the utility from consuming the good.

We study stationary equilibria in which agents do not change their occupations; that is, producers choose to stay in the production sector and private rent-seekers stay in the rent-seeking sector. For this to be incentive compatible, the payoffs in both sectors must 
satisfy the following conditions in equilibrium:

$$
P_{p}\left\{\begin{array}{lll}
=1 & \text { if } & V_{p}-c_{p}>V_{\gamma} \\
\in[0,1] & \text { if } & V_{p}-c_{p}=V_{\gamma} \\
=0 & \text { if } & V_{p}-c_{p}<V_{\gamma} .
\end{array}\right.
$$

If there are any private rent-seekers in equilibrium, $V_{\gamma} \geq V_{p}-c_{p}$. For producers to be active in the economy, the payoffs must satisfy $V_{p}-c_{p} \geq V_{\gamma}$. Thus, for both producers and private rent-seekers to stay in their respective occupations, we must have $V_{p}-c_{p}=V_{\gamma}{ }^{6}$

Definition 1. A stationary equilibrium with an exogenous bureaucracy is a list of value functions $\left(V_{p}, V_{\gamma}\right)$ and a distribution $\left(P_{p}, P_{\gamma}\right)$ satisfying (2) and (3), the government budget constraint (1) and the best response conditions (4).

We restrict our attention to nondegenerate equilibria in which production and consumption take place, given the size of bureaucracy $P_{b} \in(0,1)$. We have two types of potential equilibria in which there are positive measures of producers: one with private rent-seeking, $P_{\gamma} \in(0,1)$ and the other without, $P_{\gamma}=0$. The equilibrium with $P_{p}, P_{\gamma} \in(0,1)$ implies $V_{p}-c_{p}=V_{\gamma}$. The distribution with $P_{\gamma}=0$ implies $P_{p}=1-P_{b}$, which requires $V_{p}-c_{p} \geq V_{\gamma}$ in equilibrium. We will characterize the properties of the value functions and existence of nondegenerate equilibria.

Given the government budget constraint and $P_{\gamma}=1-P_{b}-P_{p}$, we rewrite (2) and (3) in a stationary equilibrium as follows:

$$
\begin{aligned}
& r V_{p}=-\frac{P_{b} w}{P_{p}}+P_{p}\left(U-c_{p}\right)-P_{b} \phi c_{p}-\left(1-P_{b}-P_{p}\right)\left[1-e\left(P_{b}\right)\right] c_{p}, \\
& r V_{\gamma}=P_{p}\left[1-e\left(P_{b}\right)\right] U .
\end{aligned}
$$

The following lemma describes the properties of the value functions.

Lemma 1. For a given $P_{b} \in(0,1), V_{\gamma} \rightarrow 0$ and $V_{p}-c_{p}<0$ as $P_{p} \rightarrow 0 . V_{p}$ is an increasing and concave function of $P_{p}$, and $V_{\gamma}$ is an increasing and linear function of $P_{p}$. Moreover, $\frac{d V_{p}}{d P_{p}}>\frac{d V_{\gamma}}{d P_{p}}$ for all $P_{p}$.

\footnotetext{
${ }^{6}$ There are similar best response conditions for private rent-seekers. Since $P_{p}=1-P_{\gamma}-P_{b}$ and $P_{b}$ is exogenously given, we need consider only one set of conditions.
} 
From Lemma $1, V_{\gamma}>V_{p}-c_{p}$ as $P_{p} \rightarrow 0$. Hence, for the curves $V_{p}-c_{p}$ and $V_{\gamma}$ to have intersections such that $P_{p} \in\left(0,1-P_{b}\right]$, it must be that $V_{p}-c_{p} \geq V_{\gamma}$ at the point $P_{p}=1-P_{b}$ (where $P_{\gamma}=0$ ). The following proposition establishes the existence of equilibria (proofs of lemmas and propositions are in the Appendix).

Proposition 1. Given $P_{b} \in\left(\underline{P_{b}}, \overline{P_{b}}\right)$, there exist two distinct equilibria: one with private rent-seeking, $P_{\gamma} \in(0,1)$, and the other without, $P_{\gamma}=0$.

Figure 1 shows the existence of multiple equilibria. ${ }^{7}$ The equilibrium with $P_{p}^{s}$ features a smaller population of producers, while in the equilibrium with $P_{p}^{l}$ there is a larger population of producers. The $P_{p}^{s}$ equilibrium is unstable and the $P_{p}^{l}$ equilibrium is stable. To see the instability of $P_{p}^{s}$, note that an increment in $P_{p}$ beyond $P_{p}^{s}$ raises return to producers, and hence increases the incentives for production. The multiplicity of equilibria is due to a strategic complementarity (see Cooper and John, 1988). There is a direct effect whereby production by an agent creates positive externalities on the production decision of other agents: More producers make trade easier. More producers, however, also provides higher opportunities for private rent-seekers. If more talent is allocated to the private rent-seeking due to the increasing gains, there would be fewer producers to trade with, indirectly creating a negative externality on the incentive to produce. When the direct positive effect dominates the indirect negative effect, a strategic complementarity exists and leads to multiple equilibria.

To compare welfare across equilibria, we define the welfare criterion as

$$
W=P_{p} V_{p},
$$

which is the average long-run expected payoff to a producer. As in most models featuring multiple equilibria caused by strategic complementarities, the equilibria are Pareto rankable.

Proposition 2. In the economy with an exogenous bureaucracy, the equilibrium with a larger population of producers Pareto dominates the equilibrium with fewer producers.

\footnotetext{
${ }^{7}$ One of the numerical examples we find is as follows. The parameter values are $U=1.2, c_{p}=0.05$, $\phi=0.3, P_{b}=0.2, w=0.5, r=0.01$ and $e\left(P_{b}\right)=2 P_{b}$. The values of $\left(P_{\gamma}, P_{p}\right)$ in the two equilibria are $\left(P_{\gamma}^{l}, P_{p}^{l}\right)=(0,0.8)$ and $\left(P_{\gamma}^{s}, P_{p}^{s}\right)=(0.303,0.497)$.
} 
Proposition 2 is obvious from the observation that welfare $W$ is increasing in $P_{p}$ (since $\frac{d V_{p}}{d P_{p}}>0$, for all $\left.P_{p}\right)$.

Given that the equilibrium with a larger population of producers, $P_{p}^{l}$, Pareto dominates the other, $P_{p}^{s}$, a natural question would be: whether and how the government can choose a size of bureaucracy to establish the superior equilibrium as the unique outcome. This amounts to choosing a size of bureaucracy, $P_{b}^{u}$, such that the only intersection of the two curves $V_{p}-c_{p}$ and $V_{\gamma}$ is at the point $P_{p}=1-P_{b}^{u}$. From the proof of proposition 1 we know that, if $P_{b}=\underline{P_{b}}$ or $P_{b}=\overline{P_{b}}$, there exists a unique equilibrium with $P_{\gamma}=0$. Hence, by choosing the size of bureaucracy $P_{b}^{u}=\underline{P_{b}}$ or $P_{b}^{u}=\overline{P_{b}}$, the government can establish the equilibrium with a larger population of producers as the unique outcome. ${ }^{8}$

Another welfare issue regards the optimal size of bureaucracy. Let $P_{b}^{*}$ denote the size of bureaucracy to achieve the constrained optimum; i.e.,

$$
\begin{gathered}
P_{b}^{*}=\underset{P_{b}}{\arg \max } W \\
\text { s.t. } V_{p}-c_{p} \geq V_{\gamma} .
\end{gathered}
$$

Note that $W$ is increasing in $P_{p}$, so $P_{b}^{*}$ should be such that $P_{\gamma}=0$. From the above discussion we know that, when $P_{b}=\underline{P_{b}}$ or $P_{b}=\overline{P_{b}}, P_{\gamma}=0$. Moreover,

$$
\left.\frac{\partial W}{\partial P_{b}}\right|_{P_{\gamma}=0}=-V_{p}-\left(1-P_{b}\right)\left[\frac{w}{\left(1-P_{b}\right)^{2}}-\phi c_{p}-\left(U-c_{p}\right)\right]<0 ;
$$

that is, an increase in the size of bureaucracy always decreases welfare when $P_{\gamma}=0$. Therefore, to achieve the highest welfare while maintaining the private incentives to produce, the government should choose the size of bureaucracy at $\underline{P_{b}}$.

Proposition 3. The optimal size of bureaucracy is $P_{b}^{*}=\underline{P_{b}}$.

Since the suppression of expropriation is an important element of a favorable social infrastructure, we now study the effects of government policy in suppressing private and public rent-seeking on output and welfare. To this end, we assume, without loss

\footnotetext{
${ }^{8}$ Although when $P_{b}=\underline{P_{b}}, V_{p}-c_{p}=V_{\gamma}$, people are indifferent from being a producer and a rent-seeker, the stability of the equilibrium $P_{p}^{l}$ implies that a small perturbation of increasing the incentive to produce will result in more producers and, consequently, $P_{\gamma}=0$.
} 
of generality, $e\left(P_{b}\right)=\alpha P_{b}$, where $\alpha$ represents the marginal efficiency of government enforcement and $0<\alpha<\infty$. A higher $\alpha$ lowers the return to private rent-seekers, while reduces producer's expected loss caused by private rent-seeking and, hence, increases the returns to production. That is, a higher $\alpha$ shifts the curve $V_{p}-c_{p}$ upward, while shifts $V_{\gamma}$ downward. As a result, the equilibrium population of producers $P_{p}^{s}$ becomes smaller, while $P_{p}^{l}$ is unchanged (since $P_{p}^{l}=1-P_{b}$ and $P_{b}$ is given). An increase in $\alpha$ always raises welfare for equilibrium $P_{p}^{l}$ since $V_{p}$ is higher, whereas lowers welfare for equilibrium $P_{p}^{s}$ due to lower $V_{p}$ and a smaller population of producers. (Recall that after the shifts, the intersection of the two curves $V_{p}-c_{p}$ and $V_{\gamma}$ lies in the southwest of the initial intersection, which implies lower value of $V_{p}$.) We also consider the effects of a more favorable social infrastructure, such as improved legal system and political institutions, that lowers the degree of corruption. A lower $\phi$ increases producers' payoff but does not affect the returns to private rent-seekers; i.e., $V_{p}$ curve shifts upward and $V_{\gamma}$ is unchanged. As a result, $P_{p}^{s}$ becomes smaller and $P_{p}^{l}$ is unchanged. Reducing the degree of corruption always increases welfare for equilibrium $P_{p}^{l}$, whereas lowers welfare for equilibrium $P_{p}^{s}$.

The effect on production and welfare of the improved quality of government, measured by the efficiency of suppressing private and public rent-seeking, may not be the same if the allocation of talent to bureaucracy is determined endogenously. We turn to the version of the model with an endogenous bureaucracy in next section.

\section{An endogenous bureaucracy}

We now endogenize the population distribution of bureaucrats. The value functions of producers and private rent-seekers still satisfy Bellman's equations in (2) and (3), respectively. Let $V_{b}$ denote the life-time expected utility of a bureaucrat. Since now an agent can choose to be a producer, private rent-seeker or bureaucrat, we let $\Pi=$ $\max \left(V_{p}-c_{p}, V_{\gamma}, V_{b}\right)$ denote the expected value to an agent without inventory. The value function of a bureaucrat satisfies

$$
r V_{b}=w+P_{p} \phi U+\Pi-V_{b}
$$


Equation (7) says that the flow payoff to a bureaucrat is the wage and bribes collected from producers.

A producer's decision as whether or not to stay in the production sector is stated in (4). The best response conditions for a bureaucrat is described by

$$
P_{b} \begin{cases}=1 & \text { if } \quad V_{b}>V_{p}-c_{p} \\ \in[0,1] & \text { if } \quad V_{b}=V_{p}-c_{p} \\ =0 & \text { if } \quad V_{b}<V_{p}-c_{p} .\end{cases}
$$

Definition 2. A stationary equilibrium is a list of value functions $\left(V_{p}, V_{b}, V_{\gamma}\right)$ and distribution $\left(P_{p}, P_{b}, P_{\gamma}\right)$ satisfying (2), (3) and (7), the government budget constraint (1) and the best response conditions (4) and (8).

\subsection{Equilibria}

To look for nondegenerate equilibria, we first rule out the case $P_{b}=0$. To see this, substituting $P_{b}=0$ into (2), (3) and (7), one finds $V_{\gamma}>V_{p}-c_{p}$, which implies $P_{p}=0$ and the economy is degenerate. Therefore, we are left with two types of potential equilibria with positive measures of producers and bureaucrats: one with private rent-seeking, $P_{\gamma} \in(0,1)$, and the other without, $P_{\gamma}=0$.

We first discuss the equilibrium with private rent-seeking, $P_{b}, P_{p}, P_{\gamma} \in(0,1)$, which requires $V_{p}-c_{p}=V_{b}=V_{\gamma}$. To show the existence of equilibrium, we solve for $P_{\gamma}=\tilde{P}_{\gamma}\left(P_{b}\right)$ from $V_{b}=V_{\gamma}$ as follows:

$$
\tilde{P}_{\gamma}=1-P_{b}-\frac{w}{\left(1-e\left(P_{b}\right)-\phi\right) U} .
$$

Substitute $\tilde{P}_{\gamma}\left(P_{b}\right)$ into (5) and (7) and take total differentiation with respect to $P_{b}$ to find the properties of $V_{b}$ and $V_{p}$.

Lemma 2. $V_{b}$ is strictly increasing and convex in $P_{b}$, and $V_{p}$ is convex in $P_{b}$.

Given $\tilde{P}_{\gamma}$ defined in (9), we find $V_{b}>V_{p}-c_{p}$ as $P_{b} \rightarrow 0$ for all parameters. For the curves $V_{b}$ and $V_{p}-c_{p}$ to have an intersection such that $P_{\gamma} \in(0,1)$, it must be that $V_{p}-c_{p}>V_{b}$ as $P_{\gamma} \rightarrow 0$. Given $\frac{\partial \tilde{P}_{\gamma}}{\partial P_{b}}<0$ (proof in the Appendix) this amounts to finding a point of $P_{b}$ 
(denoted $\hat{P}_{b}$ ) such that $\tilde{P}_{\gamma}\left(\hat{P}_{b}\right)=0$ and $V_{p}\left(\hat{P}_{b}\right)-c_{p}>V_{b}\left(\hat{P}_{b}\right) .{ }^{9}$ This implies that, given other parameters, the marginal efficiency of bureaucrats and the degree of corruption must be such that $\hat{P}_{b}(\alpha, \phi) \in(0,1)$ and $V_{p}\left(\hat{P}_{b}\right)-c_{p}>V_{b}\left(\hat{P}_{b}\right)$ for the equilibrium to exist. From numerical examples we find that the quality of bureaucracy is key to the existence of equilibrium: The efficiency in suppressing private and public expropriation must be sufficient; i.e., $\alpha$ must be high and $\phi$ low enough, to ensure $V_{p}\left(\hat{P}_{b}\right)-c_{p}>V_{b}\left(\hat{P}_{b}\right)$. Figure 2 shows the existence of equilibrium with private rent-seeking. The point $P_{b}^{o}$ in Figure 2 is the value of $\hat{P}_{b}$ such that $\tilde{P}_{\gamma}\left(\hat{P}_{b}\right)=0$.

We now turn to the equilibrium without private rent-seeking, $P_{b}, P_{p} \in(0,1)$ and $P_{\gamma}=0$, which requires $V_{p}-c_{p}=V_{b} \geq V_{\gamma}$. The following lemma describes the properties of the value functions.

Lemma 3. When $P_{\gamma}=0, V_{p}$ is concave in $P_{b}$, and $V_{b}$ is a decreasing and linear function of $P_{b}$.

Since $V_{p}-c_{p}<V_{b}$ as $P_{b} \rightarrow 1$, if the condition $V_{p}\left(\hat{P}_{b}\right)-c_{p}>V_{b}\left(\hat{P}_{b}\right)$ is satisfied, there exists an equilibrium with $P_{\gamma}=0$, shown in Figure 3 .

Proposition 4. If the efficiency of government in suppressing private and public rentseeking is sufficiently high, there exist two equilibria with active producers and bureaucrats: one with private rent-seeking, $P_{\gamma} \in(0,1)$, and the other without, $P_{\gamma}=0$.

Note that the equilibrium with private rent-seeking features a smaller bureaucracy, while the equilibrium without private rent-seeking features a larger bureaucracy. ${ }^{10}$ The multiplicity of equilibria is also due to a strategic complementarity, but in the current version one must take into consideration the effect on resource allocation of the endogenous changes in the size of bureaucracy. An increase in production has direct positive

${ }^{9}$ From $(9), \tilde{P}_{\gamma}\left(\hat{P}_{b}\right)=0$ can be solved for

$$
\hat{P}_{b}=\frac{(1+\alpha-\phi)-\sqrt{(1+\alpha-\phi)^{2}-4 \alpha(1-\phi-w / U)}}{2 \alpha} .
$$

\footnotetext{
${ }^{10}$ One may wonder whether it's possible to have a unique equilibrium. In principle, when $V_{p}\left(\hat{P}_{b}\right)-c_{p}=$ $V_{b}\left(\hat{P}_{b}\right)$ there exists a unique equilibrium where $P_{\gamma}=0$. Since $P_{b}$ is endogenously determined in this model, the set of parameters under which this case occurs is of measure zero (also see Diamond 1982).
} 
externalities on the returns to producers, bureaucrats, and private rent-seekers. This could lead to an increase in the populations of rent-seekers and bureaucrats and, hence, bring a negative externality to discourage production. This indirect negative effect, however, is lessened by the fact that a larger bureaucracy deters private rent-seeking, which further magnifies the direct positive effect. Indeed, our simulation results show that the positive effect dominates, and a strategic complementarity results in multiple equilibria.

In the version with an endogenous bureaucracy, we use

$$
W=P_{p} V_{p}+P_{b} V_{b}
$$

as the welfare criterion. Note that this model features a general equilibrium framework with endogenous transaction patterns. Since policies that change the quality of government may affect the transaction patterns and the way that the bureaucracy is involved in the economy, a model featuring endogenous transaction patterns can free the welfare analysis from the Lucas critique, as argued by Shi and Temzelides (2004).

Table 1 summarizes the comparison in welfare and allocation of talent between the two equilibria. ${ }^{11}$ First note that the size of bureaucracy affects the incentives to produce and welfare through two channels. One is the positive effect on production through better property rights protection. The other includes the negative effects due to corruption, higher tax burdens and the negative externality on the probability to trade, all of which reduce the return to producers. In the economy with an endogenous bureaucracy, the positive effect is magnified through deterring private rent-seeking. Indeed, we find that the equilibrium with a larger bureaucracy is associated with higher production, and is Pareto superior.

Note that for neither of the two equilibria is the size of bureaucracy optimal. Table 1 shows that, for the equilibrium with a smaller bureaucracy, the size of bureaucracy is too large, while for the equilibrium with a larger bureaucracy, it is too small. One resulting implication is that, when an economy is in the equilibrium with a smaller bureaucracy,

\footnotetext{
${ }^{11}$ The parameter values are $U=1.2, w=0.15, c_{p}=0.1, r=0.01, e\left(P_{b}\right)=\alpha P_{b}$ in the examples of Table 1 and 2. Note that $P_{b}^{o}$, that corresponds to $\tilde{P}_{\gamma}\left(P_{b}^{o}\right)=0$, is the optimal size of bureaucracy. The argument is similar to that in section 3 .
} 
it pays to increase the size of bureaucracy to deter private rent-seeking even though the bureaucrats are corrupt.

We also observe the effects of government suppression in private and public rentseeking on the allocation of talent and welfare from Table 1. As in the benchmark model, a higher $\alpha$ or lower $\phi$ also reduces the population of producers in the equilibrium with a smaller bureaucracy. However, in the equilibrium with a larger bureaucracy, changes in $\alpha$ have no effects on resource allocations. The reason is that, in this equilibrium, $P_{\gamma}=0$, so the improved efficiency in deterring private rent-seeking has no real effects. A lower $\phi$, however, raises the size of bureaucracy but lowers the population of producers and welfare. This result is due to the following general equilibrium effect: a lower degree of corruption, $\phi$, lowers the value to a bureaucrat, $V_{b}$, but raises $V_{p}$. For $V_{p}-c_{p}=V_{b}$ to hold in equilibrium, it must be that the population of producers is lower. This result is different from the basic model due to a general equilibrium effect through affecting the payoffs to bureaucrats that is not captured in the model with an exogenous bureaucracy. ${ }^{12}$

\subsection{The Size of Government}

Many believe that the size of government is an important factor for determining economic performance; however, as argued by Hall and Jones (1999), the size of government should better be thought as outcomes rather than determinants. We will demonstrate in the following analysis that, the size of government and economic performance are jointly determined in our model, and their relationship is influenced by the quality of government.

Let $g$ denote the size of government, defined as government spending relative to output per capita:

$$
g=P_{b} w / P_{p}
$$

\footnotetext{
${ }^{12}$ As the referee pointed out, one may be curious about the relative effectiveness of taxes versus corruption as a means to support the bureaucracy. From numerical examples we found that, in the equilibrium with rent-seekers, when we increase taxes (so bureaucrats get higher wages) and decrease the degree of corruption so as to keep bureaucrats as well off as the benchmark case, welfare is higher. Therefore, taxes are a more effective means to support the bureaucracy. However, welfare does not change in the equilibrium without rent-seeking.
} 


\begin{tabular}{ccc|ccc|ccc}
\hline & & $\begin{array}{c}\text { Optimal Size } \\
\text { of Bureaucracy }\end{array}$ & \multicolumn{3}{c}{ Equilibrium With } & \multicolumn{5}{c}{ Equilibrium With } \\
& & $P_{b}^{o}$ & $P_{p}$ & $P_{b}$ & $W$ & $P_{p}$ & $P_{b}$ & $W$ \\
\hline$\phi=0.3$ & $\alpha=1.3$ & 0.38 & 0.39 & 0.30 & 0.20 & 0.46 & 0.54 & 0.32 \\
& $\alpha=1.4$ & 0.36 & 0.38 & 0.27 & 0.19 & 0.46 & 0.54 & 0.32 \\
& $\alpha=1.5$ & 0.34 & 0.37 & 0.25 & 0.18 & 0.46 & 0.54 & 0.32 \\
\hline$\alpha=1.4$ & $\phi=0.2$ & 0.41 & 0.36 & 0.32 & 0.16 & 0.42 & 0.58 & 0.25 \\
& $\phi=0.3$ & 0.36 & 0.38 & 0.27 & 0.18 & 0.46 & 0.54 & 0.32 \\
& $\phi=0.4$ & 0.30 & 0.42 & 0.22 & 0.22 & 0.51 & 0.49 & 0.39 \\
\hline
\end{tabular}

Table 1. Comparison of Welfare and Allocation of Talent

Under the definition (11) $g$ is identical to $\tau$, the tax payment by a producer. Since $P_{b}$ and $P_{p}$ are determined endogenously by the institutional factors, such as the degree of corruption and the efficiency of property rights protection, so are the government spending and the size of government. Therefore, the size of government, $g$, and the economic performance (measured by the output per capita, $P_{p}$ ) are jointly determined in the current model.

We focus on the equilibrium with active private rent-seeking in the following discussion. Table 2 shows the results of our simulation on the relationship between $g$ and $P_{p}$. Given other parameters, the correlation between $g$ and $P_{p}$ is positive when we vary $\alpha$, whereas it is negative when we vary $\phi$. A higher $\phi$ increases the return to bureaucrats, which results in two opposite effects on the incentive to produce: the positive effect of better property right protection, and the negative effect of higher tax burdens and corruption. The former effect dominates the latter, and thus, the return to production increases. Consequently, $P_{p}$ increases and $P_{b}$ decrease, and therefore, $g$ decreases. Hence, we observe a negative relationship between $g$ and $P_{p}$. A higher degree of corruption affects the reward structure to such an extent that eventually more resources are devoted to productive activity.

An increase in $\alpha$ implies higher efficiency in deterring rent-seeking, which increases 


\begin{tabular}{cccccc}
\hline & & $P_{p}$ & $P_{b}$ & $P_{\gamma}$ & $g$ \\
\hline$\phi=0.3$ & $\alpha=1.3$ & 0.39 & 0.30 & 0.31 & 0.11 \\
& $\alpha=1.4$ & 0.38 & 0.27 & 0.35 & 0.10 \\
& $\alpha=1.5$ & 0.37 & 0.25 & 0.38 & 0.09 \\
\hline$\alpha=1.4$ & $\phi=0.2$ & 0.36 & 0.32 & 0.32 & 0.13 \\
& $\phi=0.3$ & 0.38 & 0.27 & 0.35 & 0.10 \\
& $\phi=0.4$ & 0.42 & 0.22 & 0.36 & 0.08 \\
\hline
\end{tabular}

Table 2. Equilibrium with Private Rent-seeking

the incentive to produce. Higher production results in a direct positive externality and an indirect negative externality, as explained in subsection 4.1. It turns out that the negative effect dominates the positive effect, so eventually both $P_{p}$ and $P_{b}$ decline while $P_{\gamma}$ increases. This general equilibrium result implies that higher efficiency in deterring private rent-seeking can sustain an economy with a smaller size of bureaucracy and more private rent-seekers. The numerical examples show that the size of government $g$ declines because $P_{b}$ decreases more than $P_{p}$ does, and thus, there is a positive relationship between $g$ and $P_{p}$.

The main message we wish to deliver from the numerical examples is that, the relationship between the size of government and output per capita is not conclusive; it depends on the quality of government. This result is in line with some empirical studies on cross-country data that do not find a conclusively negative relationship between the size of government and output per capita. ${ }^{13}$

\footnotetext{
${ }^{13}$ Slemrod and Bakija (1996) found that, in a survey of OECD countries over the 1970-1990 period, there was no significant correlation between the size of government (taxes as a percentage of GDP) and GDP per capita.
} 


\section{Conclusion}

The government is modeled here as a 'minimal state' or 'night-watch state', limited to the functions of protecting all its citizens against private rent-seekers (see Friedman 1962 and Nozick 1974); however, bureaucrats are also a source of rent-seeking. We show that bureaucrats' efficiency in suppressing private rent-seeking and the degree of corruption are key to the existence of equilibrium. In the version with exogenously given bureaucrats, if the government can choose the size of a bureaucracy, then a smaller bureaucracy is associated with higher production and welfare. If the size of bureaucracy is endogenously determined, however, the equilibrium with a larger bureaucracy features a reward structure that enhances production and welfare, as long as bureaucrats' efficiency is high and corruption is low. Our model thus demonstrates that whether or not to endogenize bureaucracy matters for the welfare implications. In this paper, the size of government and economic performance are jointly determined in the current model, and their relationship depends on the quality of bureaucracy. Thus the size of government may not be a primary concern for improving an economy's performance since both are jointly determined; what is important is the quality of government. 


\section{Reference}

Acemoglu, Daron (1995) 'Reward Structures and the Allocation of Talent,' European Economic Review 39, 17-33.

Acemoglu, Daron and Verdier, Thierry (1998) 'Property Rights, Corruption and the Allocation of Talents: A General Equilibrium Approach,' The Economic Journal 108, 1384-1403.

Barreto, Raul (2000), 'Endogenous corruption in a neoclassical growth,' European Economic Review 44, 35-60.

Baumol, William (1990), 'Entrepreneurship: Productive, Unproductive and Destructive,' Journal of Political Economy 98, 270-293.

Burdett, Kenneth, Lagos, Ricardo and Wright, Randall (2003), 'Crime, Inequality, and Unemployment,' American Economic Review 93, 1764-1777.

Cooper, Russell and John, Andrew (1988), 'Coordinating coordination failures in Keynesian models,' Quarterly Journal of Economics 103, 441-463.

Cameron, Samuel (1988), 'The Economics of Crime Deterrence: A Survey of Theory and Evidence,' Kyklos, 41, 301-323.

Diamond, Peter (1982), 'Aggregate Demand Management in Search Equilibrium,' Journal of Political Economy 90, 881-894.

Di Tella, Rafael and Schargrodsky, Ernesto (2004),'Do Police Reduce Crime? Estimates Using the Allocation of Police Forces After a Terrorist Attack,' American Economic Review, 94, 115-133.

Friedman, Milton (1962), Capitalism and Freedom. Chicago: University of Chicago Press.

Hall, Robert E. and Jones, Charles I (1999), 'Why Do Some Countries Produce So Much More Output per Worker than Others?' Quarterly Journal of Economics 114, 83-116. 
Klick, Jonathan and Tabarrok, Alexander (2005), 'Using Terror Alert Levels to Estimate the Effect of Police on Crime,' Journal of Law and Economics, 48, 267-279.

Kugler, Maurice, Verdier, Thierry and Zenou, Yves (2005), 'Organized crime, corruption and punishment,' Journal of Public Economics, 89, 1639-1663.

Li, Yiting and Wright, Randall (1998), 'Government Transaction Policy, the Media of Exchange and Prices,' Journal of Economic Theory 81, 290-313.

Murphy, Kevin M., Shleifer, Andrei and Vishny, Robert W. (1991), 'The Allocation of Talent: Implications for Growth,'Quarterly Journal of Economics 106, 503-530.

Murphy, Kevin M., Shleifer, Andrei and Vishny, Robert W. (1993), 'Why Is RentSeeking So Costly to Growth?' American Economic Review 83, 409-14.

Nozick, Robert (1974), Anarchy, State, and Utopia. New York : Basic Books 1974.

Shi, Shouyong and Temzelides, Ted (2004), 'A Model of Bureaucracy and Corruption,' International Economic Review 45, 873-908.

Slemrod, Joel and Bakija, Ron (1996), Taxing Ourselves: A Citizen's Guide to the Great Debate over Tax Reform. Cambridge, Mass: MIT Press. 


\section{Appendix}

\section{Proof of Lemma 1.}

Given value functions $V_{\gamma}$ and $V_{p}$, one finds $V_{\gamma} \rightarrow 0$ and $V_{p} \rightarrow-\infty$, as $P_{p} \rightarrow 0$. Take total differentiation for $V_{\gamma}$ and $V_{p}$, we find:

$$
\begin{aligned}
\frac{d V_{p}}{d P_{p}} & =\frac{1}{r}\left\{\frac{P_{b} w}{P_{p}^{2}}+U-c_{p}+\left[1-e\left(P_{b}\right)\right] c_{p}\right\}>0, \\
\frac{d^{2} V_{p}}{d P_{p}^{2}} & =\frac{1}{r}\left\{\frac{-2 P_{b} w}{P_{p}^{3}}\right\}<0, \\
\frac{d V_{\gamma}}{d P_{p}} & =\frac{1}{r}\left\{\left[1-e\left(P_{b}\right)\right] U\right\}>0, \\
\frac{d^{2} V_{\gamma}}{d P_{p}^{2}} & =0 . \\
\frac{d V_{p}}{d P_{p}}-\frac{d V_{\gamma}}{d P_{p}} & =\frac{1}{r}\left\{\frac{P_{b} w}{P_{p}^{2}}+e\left(P_{b}\right)\left(U-c_{p}\right)\right\}>0 .
\end{aligned}
$$

Proof of Proposition 1.

Let $S\left(P_{p}\right)=V_{p}-V_{\gamma}-c_{p}$. In equilibrium with $P_{\gamma} \in(0,1), S\left(P_{b}\right)=0$. In equilibrium with $P_{\gamma}=0, S\left(1-P_{b}\right)>0$.First, from Lemma 1 we know $S(0)<0$. If the condition $S\left(1-P_{b}\right)>0$ holds, it suffices to show that there are two distinct equilibria. Given $e^{\prime}>0, e^{\prime \prime} \leq 0$ and $e(0) \geq 0$, we find that, at the point $P_{p}=1-P_{b}, V_{p}-c_{p} \geq V_{\gamma}$ iff $\underline{P_{b}} \leq P_{b} \leq{\overline{P_{b}}}^{\prime}$. We also need to check whether $V_{\gamma} \geq 0$. There is a lower bound ${\overline{P_{b}}}^{\prime \prime}$ such that if $P_{b} \geq{\overline{P_{b}}}^{\prime \prime}, V_{\gamma} \leq 0$, for all $P_{p} \in\left(0,1-P_{b}\right]$. Let $\overline{P_{b}}=\min \left\{{\overline{P_{b}}}^{\prime},{\overline{P_{b}}}^{\prime \prime}\right\}$. Then, if the condition $\underline{P_{b}} \leq P_{b} \leq \overline{P_{b}}$ holds, $S\left(1-P_{b}\right)>0$ and there exist two distinct equilibria. Proof of Lemma 2.

Here we assume $1-e\left(P_{b}\right)-\phi>0$; otherwise there are no solutions. Given $V_{b}=V_{\gamma}$, $\tilde{P}_{\gamma}$ is a strictly decreasing and concave in $P_{b}$ :

$$
\begin{aligned}
\left.\frac{d \tilde{P}_{\gamma}}{d P_{b}}\right|_{V_{b}=V_{\gamma}} & =-1-\frac{w e^{\prime}\left(P_{b}\right)}{\left(1-e\left(P_{b}\right)-\phi\right)^{2} U}<0 . \\
\left.\frac{d^{2} \tilde{P}_{\gamma}}{d P_{b}^{2}}\right|_{V_{b}=V_{\gamma}} & =\frac{-2 w\left[e^{\prime}\left(P_{b}\right)\right]^{2}}{\left(1-e\left(P_{b}\right)-\phi\right)^{3} U}<0 .
\end{aligned}
$$

Substitute (9) into (5) and (7) and take total differentiation, we have 


$$
\begin{aligned}
\left.\frac{d V_{b}}{d P_{b}}\right|_{V_{b}=V_{\gamma}} & =\frac{1}{r}\left(-1-\frac{d \tilde{P}_{\gamma}}{d P_{b}}\right) \phi U>0, \\
\left.\frac{d^{2} V_{b}}{d P_{b}^{2}}\right|_{V_{b}=V_{\gamma}} & =-\frac{1}{r} \frac{d^{2} P_{\gamma}}{d P_{b}^{2}} \phi U>0 . \\
\left.\frac{d^{2} V_{p}}{d P_{b}^{2}}\right|_{V_{b}=V_{\gamma}} & =2 \alpha\left(U-c_{p}\right)+\frac{2 \alpha^{2} w}{\left(1-e\left(P_{b}\right)-\phi\right)^{3} U}\left[\left(1-e\left(P_{b}\right)-\phi\right)+\left(U-\alpha c_{p} P_{b}\right)\right]>0 .
\end{aligned}
$$

Proof of Lemma 3.

$$
\begin{aligned}
\frac{d V_{p}}{d P_{b}} & =\frac{1}{r}\left\{\frac{-w}{\left(1-P_{b}\right)^{2}}-\left(U-c_{p}\right)-\phi c_{p}\right\}, \\
\frac{d^{2} V_{p}}{d P_{b}^{2}} & =\frac{-2 w}{r\left(1-P_{b}\right)^{3}}<0 .
\end{aligned}
$$

The second equation shows the concavity of $V_{p}$.

$$
\begin{aligned}
\frac{d V_{b}}{d P_{b}} & =\frac{1}{r}(-\phi U)<0, \\
\frac{d^{2} V_{b}}{d P_{b}^{2}} & =0 .
\end{aligned}
$$

Proof of Proposition 4.

We first prove the existence of the equilibrium with private rent-seeking. Lemma 2 shows that $V_{b}$ and $V_{p}$ are monotone functions given $\tilde{P}_{\gamma}$. Let $Q\left(P_{b}\right)=V_{p}-c_{p}-V_{b}$. The equilibrium condition on $P_{b} \in(0,1)$ implies $Q\left(P_{b}\right)=0$. Since $Q(0)<0$, it suffices to show that there exist a $P_{b}$ such that $Q\left(P_{b}\right)=0$, if $V_{p}\left(P_{b}^{o}\right)-\gamma>V_{b}\left(P_{b}^{o}\right)$ with $\tilde{P}_{\gamma}\left(P_{b}^{o}\right)=0$.

To prove the existence of the equilibrium without private rent-seeking, notice that, as in the model with exogenous rent seeking, $V_{p}$ is concave and decreases in $P_{b}$, and $V_{b}$ is linear and decreases in $P_{b}$. Since $Q\left(P_{b}^{o}\right)>0$ and $Q(1)<0$, it suffices to show that there exists a $P_{b}^{* *}$ such that $Q\left(P_{b}^{* *}\right)=0$. We also need to show $V_{\gamma}<V_{b}=V_{p}-c_{p}$ at $P_{b}^{* *}$. Recall that $\tilde{P}_{\gamma}\left(P_{b}^{o}\right)$ is solved from $V_{b}=V_{\gamma}$ and $P_{b}^{o}$ is such that $\tilde{P}_{\gamma}\left(P_{b}^{o}\right)=0$. Since $V_{\gamma}$ is a decreasing function of $P_{b}$, it must be that $V_{\gamma}<V_{b}$ at $P_{b}=P_{b}^{* *}>P_{b}^{o}$ 


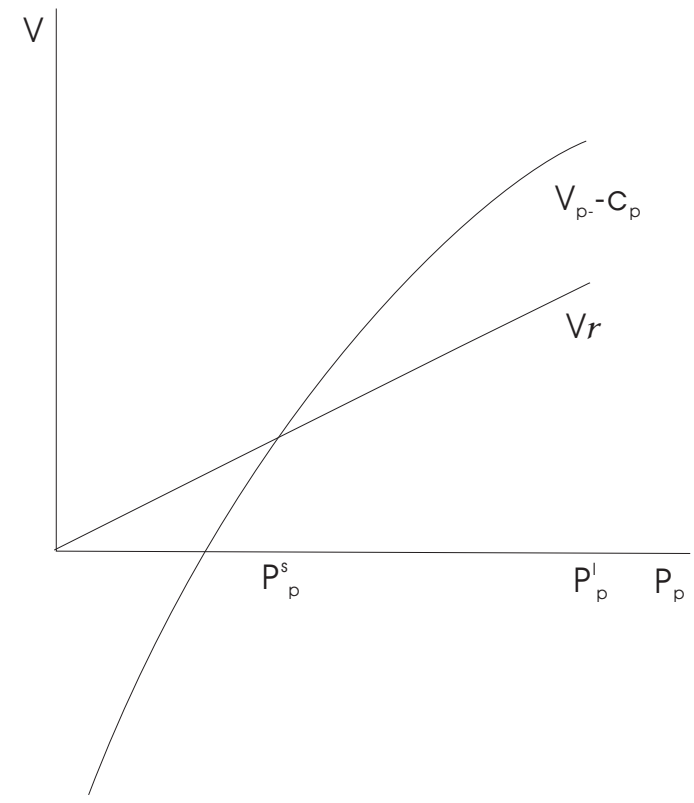

Figure 1. Equilibrium with exogenous bureaucracy

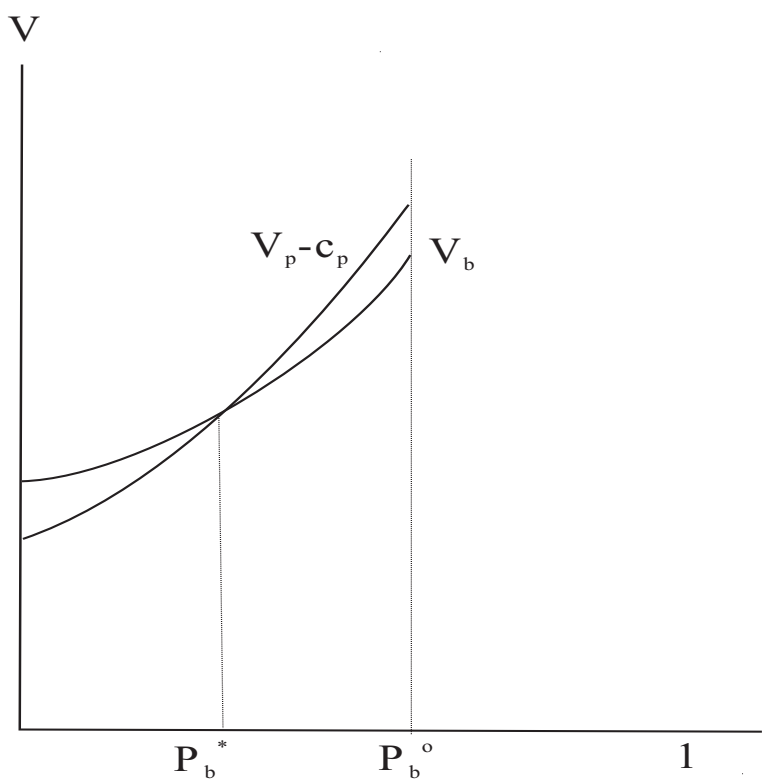

Figure 2. Equilibrium with private rent-seeking 


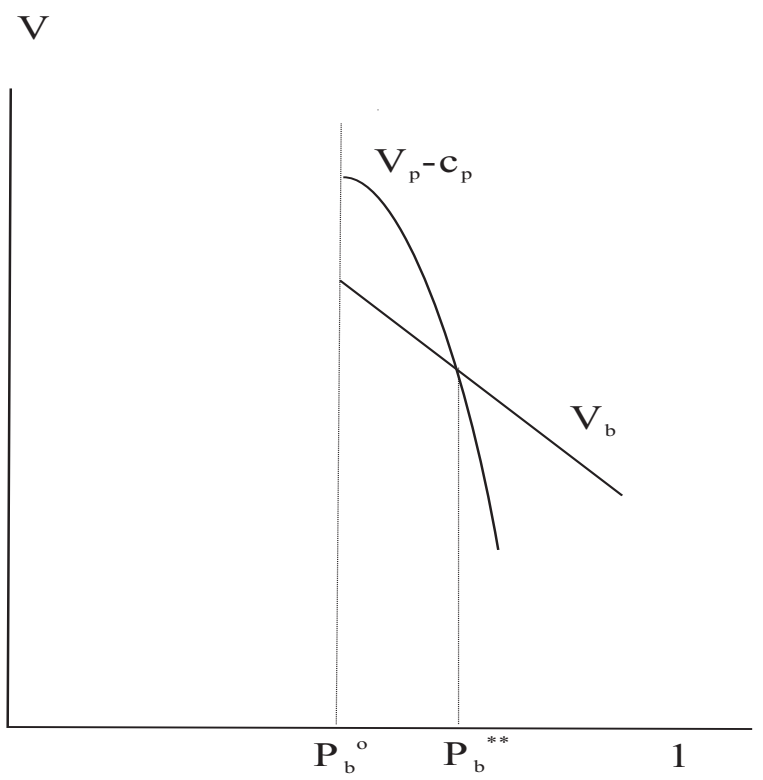

Figure 3. Equilibrium without private rent-seeking 